\title{
COMPARISON OF AIRBORNE LASER SCANNING OF LOW AND HIGH ABOVE GROUND LEVEL FOR SELECTED INFRASTRUCTURE OBJECTS
}

\author{
J. Siwiec a \\ ${ }^{\text {a }}$ AGH University of Science and Technology, Faculty of Mining Surveying and Environmental Engineering, Department of \\ Engineering Surveying and Civil Engineering, al. Mickiewicza 30, 30-059 Kraków, Poland, e-mail: jsiwiec@agh.edu.pl
}

Received: 14.10.2018 / Accepted: 12.11.2018/ Revised: 20.11.2018 / Available online: 15.12.2018

DOI: 10.2478/jaes-2018-0023

KEY WORDS: Lidar, UAV, airborne scanning, monitoring, infrastructure

\begin{abstract}
:
Along with the development of the technology of drone construction (UAV - Unmanned Aerial Vehicles), the number of applications of these solutions in the industry also grew. The aim of the research is to check the accuracy of data obtained using the new technology of UAV scanning and to compare them with one that is widely spread - high-altitude airborne Lidar, in terms of quality and spectrum of applications in industry and infrastructure. The research involved two infrastructure objects: a reinforced concrete one-span bridge and Lattice transmission tower with powerlines. The density of measurement, internal and external cohesion of point clouds obtained from both methods were compared. Plane fitting and deviation analysis were used. The data of UAV origin in both cases provided a sufficient density, allowing the recognition of structural elements, and internal coherence and precision of measurements important in modeling. The study shows that UAV mounted scanning may be used in the same applications as Airborne Lidar, as well as in other tasks requiring greater precision.
\end{abstract}

\section{INTRODUCTION}

Lidar - Light Detection and Ranging is mainly associated with airborne laser scanning. In contrast to terrestrial scanning, it enables coverage of large areas, including areas not available for measurement from the ground.

With the development of UAV technology, the number of applications of these solutions in industry grew. The popularity of photogrammetric systems based on non-metric digital cameras mounted on a multicopter or fixed-wing planes (Ham, Y., et al., 2016). These systems characteristic was a small mass of measuring equipment (cameras) and positioning systems operating in autonomous mode (GNSS solution). In order to process the measurement data, the use of GCP was also necessary. GCP - Ground Control Points are photo points, which ensure a proper spatial reference (external orientation of the created model) in the post processing (Colomina, I., \& Molina, P., 2014). For technical reasons, airborne scanning was previously reserved for aircraft. It was caused by a large mass and size of scanners and devices necessary to determine the exact position of the measurement system in time and space, with parameters of the angular orientation of the system. In contrast to aerial photographs, scanning to maintain high measurement precision requires knowledge of the exact position and spatial orientation of the system. Images has the possibility to recalculate this position during aerial triangulation - using the points identified in different pictures as identical, which combine photos into a coherent model ensuring the orientation of photos between themselves, and ground-based points of known coordinates (AICARDI, I., et al., 2016).
The need to determine the exact position of the scanner during the measurement results from the characteristics of the mobile scanning, where each measured scan line must have a known spatial position - orientation along the trajectory (Kukko, A. et al., 2012). This is the main difference between mobile and terrestrial laser scanning (TLS). Principle of the TLS is stationary position of one setup - scan station. In the case of mobile scanning either ground based or airborne, the current accuracy of the position along trajectory is ensured by the integration of the RTK GNSS system and the IMU inertial unit (Brede, B., et al., 2017).

The main principle of this system is the combination of discrete observations with RTK GNSS - positions with observations of a stationary station receiver with known coordinates. The role of a base station can be fulfilled by a single GPS receiver or a network of reference stations. Positions between consecutive positions calculated from GNSS postprocessing are supplemented with observations from an inertial unit composed of a set of accelerometers. Thanks to the common alignment of observations, the internal precision of the trajectory geometry is improved, while the GNSS postprocessing ensures the accuracy of the global location at the level of single centimeters (Hutton, J., et al., 2007). The use of the INS-GPS RTK system enables measurement without the use of additional ground measurements (Mian, O., et al., 2015).

Miniaturization of these systems and the creation of light laser scanners, made it possible to install these devices on unmanned aerial systems, without compromising the accuracy of the result. 
Instruments mounted on the UAV are characterized by lower signal power. As method remains unchanged, the scale and difference of distance to measured object makes it possible to obtain a result with greater precision and consistency.

The aim of the work was to compare the data obtained from two Lidar measurement methods - high and low above ground level scanning.

\section{MATERIALS AND METHODS}

The study was carried out on the example of two infrastructure facilities, transmission tower high voltage lines and a concrete bridge. For both of the studied areas, a point cloud obtained from the Lidar flight was obtained from the PZGiK (State Geodetic and Cartographic Resource) resource. It was measured within the ISOK project using the Riegl LMS-Q680i scanner with the following parameters, mounted on lightweight airplane (Figure 1):

Maximum rate of effective measurement is up to $266 \mathrm{kHz}$ at scan angle of 60 degrees $\left(-30^{\circ} ;+30^{\circ}\right)$. Maximum range of measurement at signal frequency of $400 \mathrm{kHz}$ spans from $1000 \mathrm{~m}$ $-1600 \mathrm{~m}$ depending from reflectivity of the material. Angular step - resolution between measurements is $0.002^{\circ}$. Laser Beam Divergence - angular measure of the radius of the beam footprint increase is less than $0.5 \mathrm{mrad}$, which means that in the distance of $1000 \mathrm{~m}$ laser beam footprint would reach approximately $500 \mathrm{~mm}$ diameter. Scanner allows for measure unlimited number of targets (echoes) (Riegl, 2012). It is usually mounted on light aircrafts with typical above ground level between 900 and $1000 \mathrm{~m}$.

The same objects were also subjects of scanning measurements that were performed using multicopter Riegl Ricopter (Figure 1) with the VUX-1 scanner. It is a fully integrated measuring system that is a miniature of Lidar aircraft systems.

Maximum Take-off Mass of the integrated system is $25 \mathrm{~kg}$ and contains both UAV platform and scanner with equipment. The scanner is equipped with a near infrared laser, operating at a frequency of up to $550 \mathrm{kHz}$, at which the maximum effective range is from $170-300 \mathrm{~m}$. The minimum angular step between laser shots is $0.006^{\circ}$. The divergence of the laser beam is maintained at less than $0.5 \mathrm{mrad}$ - the same as in the LMSQ680i scanner, which means that within the effective measurement range of $100 \mathrm{~m}$ the diameter of the laser spot is 50 $\mathrm{mm}$. VUX-1 also supports echo measurement. The effective angle range of the measurement includes a spectrum of 330 degrees, $165^{\circ}$ in each side (Riegl, 2017). The blind field only includes the construction of the UAV platform. The typical altitude above ground level usually does not exceed $150 \mathrm{~m}$.

Scanner is integrated with inertial unit INS/GNSS Applanix AP20, that assure accuracy of position of $0.05 \mathrm{~m}$ horizontally and $0.10 \mathrm{~m}$ vertically.
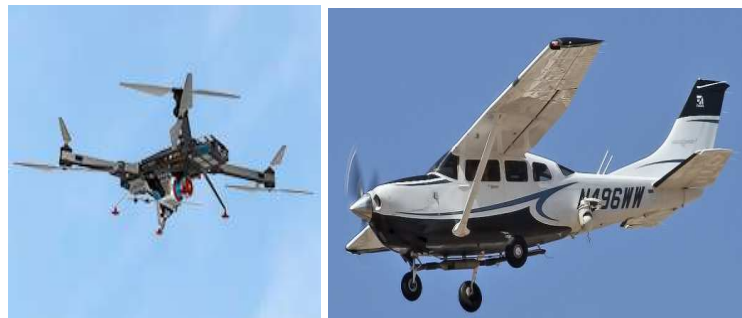

Figure 1. UAV Riegl RiCopter (left) and plane Cessna T206H (right)

\section{CASE 1 - CONCRETE BRIDGE}

Bridges, like other infrastructure objects, require monitoring and regular measurement. New Non-Destructive Testing methods join widely used visual methods. These NDT methods include laser terrestrial scanning and photogrammetric methods (Valença, J., et al., 2017). TLS offers dense and precise measurement, but in many cases, with more complex structure and geometry, it lacks the field of view and may be insufficient to cover inaccessible, obscured parts (Bolourian, N., et al., 2017). The use of UAV, both photographic and equipped with a laser scanner can help overcome these defects (Rau, J. Y., et al., 2017). In the case of such a measurement, it is necessary to carefully plan the tests, the device parameters and the path of the drone flight (Bolourian, N., et al., 2017).

The case of a bridge measurement became an opportunity to compare the quality and density of data generated from air scanning of low and high AGL (Figure 2 and 3). Data from Airborne Lidar cannot be used for detailed examination of the object's condition, but it should be sufficient to determine the situational and altitude location of some of its elements, such as roads or barriers (Yen, Kin S., et al., 2011).

Both data from the Airborne Lidar and UAV flight were not adapted specifically to the characteristics of the object. Lidar data came from the public resource, while the UAV flightplan was adapted rather to surface measurements, often used to create a Digital Terrain Model.

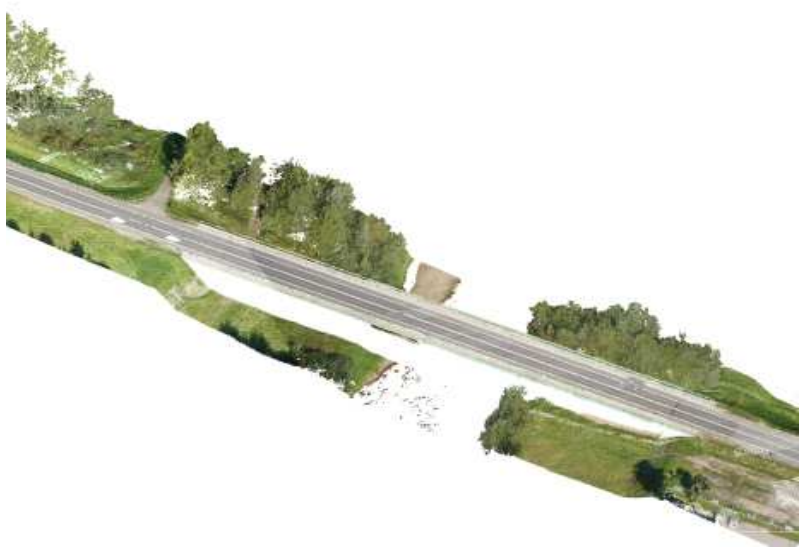

Figure 2. Isometric view of the bridge - UAV point cloud 


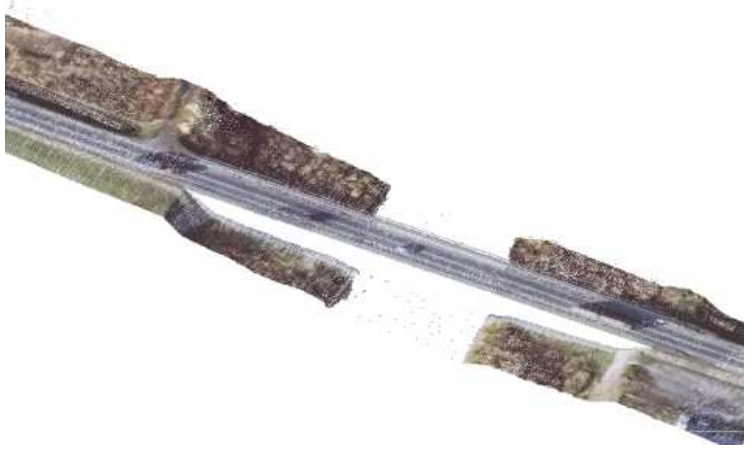

Figure 3. Isometric view of the bridge - Lidar point cloud

\subsection{Parameters of Lidar and UAV gathered data}

The Airborne Lidar mission was planned as a block of parallel scanning lines. The average AGL was $980 \mathrm{~m}$, and the distance of the scanning line from each other was not to exceed $560 \mathrm{~m}$. The signal emission frequency was $360 \mathrm{kHz}$, which resulted in an effective scanning frequency of $180 \mathrm{kHz}$. To obtain the minimum planned value of the density of the point clouds, 4.3 $\mathrm{pts} / \mathrm{m}^{2}$, the speed was set at $50 \mathrm{~km} / \mathrm{h}$. According to State Resource documentation, the resultant point cloud belonged to category I and its mean altitude error may be $0.20 \mathrm{~m}$.

The UAV flight was realized at $140 \mathrm{~m}$ AGL, with a cruising speed of $10 \mathrm{~m} / \mathrm{s}$. The measuring block consisted of parallel scanlines, which axes were $130 \mathrm{~m}$ apart from each other, which made it possible to provide sidelap of scans at $50 \%$. For aerial scanning from UAV, $90^{\circ}\left(-45^{\circ},+45^{\circ}\right)$ are considered for coverage, and the recording range has been extended to 120 degrees $\left(-60^{\circ},+60^{\circ}\right)$

Measured object was single span concrete beam bridge. Its $50 \mathrm{~m}$ span was situated $10 \mathrm{~m}$ above water surface. Cross-section of the road surface was two sided slope.

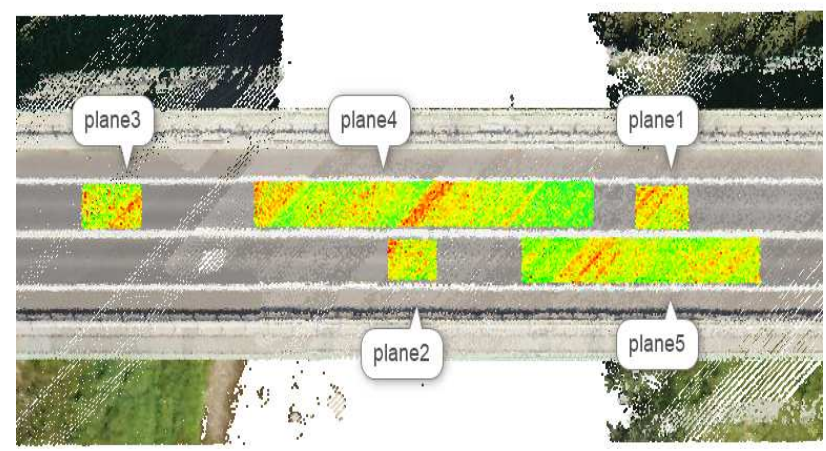

Figure 4. Location of the test fields

\subsection{Analysis:}

On the surface of the object, five test fields in the shape of rectangles were selected: three with dimensions similar to $4.5 \times 2.5 \mathrm{~m}$ and two additional covering larger area (Figure 4). In order that these fields covered only planar surface of the bridge without other objects, they were situated on the one half of the roadway and covered only a section of asphalt. Then, corresponding fragments of point clouds (Lidar and UAV) were cut out in each field. A regression plane is fitted in each slice. Planar fit statistics can be found in the tables below (Table1, 2, $3,4,5,6,7)$.

The Figure 4 shows the distribution of test fields on the bridge's roadway.

Table 1. Fitting statistics of regression plane 1

\begin{tabular}{|l|c|c|c|c|c|}
\hline Plane1 & \multicolumn{4}{|l|}{ Dimensions: $4.43 \times 2.28 \mathrm{~m}$} & \multicolumn{2}{|c|}{ Area: $10.10 \mathrm{~m}^{2}$} \\
\hline & $\begin{array}{c}\text { Number } \\
\text { of points }\end{array}$ & $\begin{array}{c}\text { Density } \\
\left(\mathrm{pt} / \mathrm{m}^{2}\right)\end{array}$ & $\begin{array}{c}\text { Max } \\
\text { dist. }(\mathrm{m})\end{array}$ & $\begin{array}{c}\text { Avg. } \\
\text { dist. }(\mathrm{m})\end{array}$ & $\begin{array}{c}\text { Sigm } \\
\mathrm{a} \\
(\mathrm{m})\end{array}$ \\
\hline Lidar: & 175 & 17.3 & 0.107 & 0.025 & 0.018 \\
\hline UAV: & 2733 & 270.6 & 0.038 & 0.006 & 0.014 \\
\hline
\end{tabular}

Table 2. Fitting statistics of regression plane 2

\begin{tabular}{|l|c|c|c|c|c|}
\hline Plane2 & \multicolumn{4}{|c|}{ Dimensions: $4.11 \times 2.68 \mathrm{~m}$} & \multicolumn{2}{|c|}{ Area: $11.02 \mathrm{~m}^{2}$} \\
\hline & $\begin{array}{c}\text { Number } \\
\text { of points }\end{array}$ & $\begin{array}{c}\text { Density } \\
\left(\mathrm{pt} / \mathrm{m}^{2}\right)\end{array}$ & $\begin{array}{c}\text { Max } \\
\text { dist. }(\mathrm{m})\end{array}$ & $\begin{array}{c}\text { Avg. } \\
\text { dist. }(\mathrm{m})\end{array}$ & $\begin{array}{c}\text { Sigma } \\
(\mathrm{m})\end{array}$ \\
\hline Lidar: & 152 & 13.8 & 0.066 & 0.027 & 0.022 \\
\hline UAV: & 1898 & 172.3 & 0.046 & 0.007 & 0.016 \\
\hline
\end{tabular}

Table 3. Fitting statistics of regression plane 3

\begin{tabular}{|l|c|c|c|c|c|}
\hline Plane3 & \multicolumn{2}{|c|}{ Dimensions: $5.14 \times 3.20 \mathrm{~m}$} & \multicolumn{2}{|c|}{ Area: $16.45 \mathrm{~m}^{2}$} & \multicolumn{2}{|c|}{$\begin{array}{c}\text { Number } \\
\text { of points }\end{array}$} & $\begin{array}{c}\text { Density } \\
\left(\mathrm{pt} / \mathrm{m}^{2}\right)\end{array}$ & $\begin{array}{c}\text { Max } \\
\text { dist. (m) }\end{array}$ & $\begin{array}{c}\text { Avg. } \\
\text { dist. (m) })\end{array}$ & $\begin{array}{c}\text { Sigma } \\
(\mathrm{m})\end{array}$ \\
\hline Lidar: & 187 & 11.4 & 0.078 & 0.021 & 0.024 \\
\hline UAV: & 1456 & 88.5 & 0.041 & 0.004 & 0.012 \\
\hline
\end{tabular}

Table 4. Summary of regression statistics (planes 1, 2, 3)

\begin{tabular}{|l|c|c|c|c|}
\hline & $\begin{array}{c}\text { Mean density } \\
\left(\mathrm{pt} / \mathrm{m}^{2}\right)\end{array}$ & $\begin{array}{c}\text { Max dist. } \\
(\mathrm{m})\end{array}$ & $\begin{array}{c}\text { Avg. dist. } \\
(\mathrm{m})\end{array}$ & $\begin{array}{c}\text { Sigma } \\
(\mathrm{m})\end{array}$ \\
\hline Lidar: & 13.7 & 0.107 & 0.024 & 0.021 \\
\hline UAV: & 162.0 & 0.046 & 0.006 & 0.014 \\
\hline
\end{tabular}

Table 5. Fitting statistics of regression plane 4

\begin{tabular}{|c|c|c|c|c|c|}
\hline Plane4 & Dimension & $8.64 \times 3$. & Area & $90.79 \mathrm{~m}^{2}$ & \\
\hline & $\begin{array}{l}\text { Number } \\
\text { of points }\end{array}$ & $\begin{array}{l}\text { Density } \\
\left(\mathrm{pt} / \mathrm{m}^{2}\right)\end{array}$ & $\begin{array}{c}\text { Max } \\
\text { dist. (m) }\end{array}$ & $\begin{array}{c}\text { Avg. } \\
\text { dist. (m) }\end{array}$ & $\begin{array}{c}\text { Sigma } \\
(\mathrm{m})\end{array}$ \\
\hline Lidar: & 1207 & 13.3 & 0.226 & 0.055 & 0.097 \\
\hline UAV: & 11618 & 128.0 & 0.226 & 0.011 & 0.049 \\
\hline
\end{tabular}

Table 6. Fitting statistics of regression plane 5

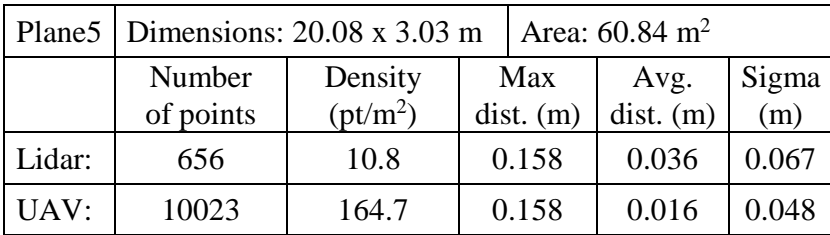

Table 7. Summary of regression statistics (planes 4, 5)

\begin{tabular}{|l|c|c|c|c|}
\hline & $\begin{array}{c}\text { Mean density } \\
\left(\mathrm{pt} / \mathrm{m}^{2}\right)\end{array}$ & $\begin{array}{c}\text { Max dist. } \\
(\mathrm{m})\end{array}$ & $\begin{array}{c}\text { Avg. dist. } \\
(\mathrm{m})\end{array}$ & $\begin{array}{c}\text { Sigma } \\
(\mathrm{m})\end{array}$ \\
\hline Lidar: & 12.3 & 0.226 & 0.046 & 0.082 \\
\hline UAV: & 142.7 & 0.226 & 0.014 & 0.049 \\
\hline
\end{tabular}




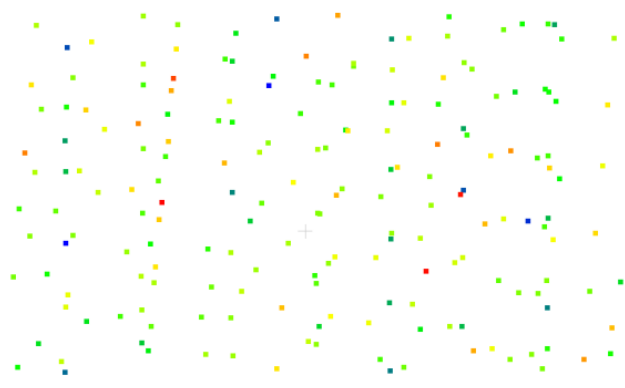

Figure 5. Map of deviations - Lidar point cloud

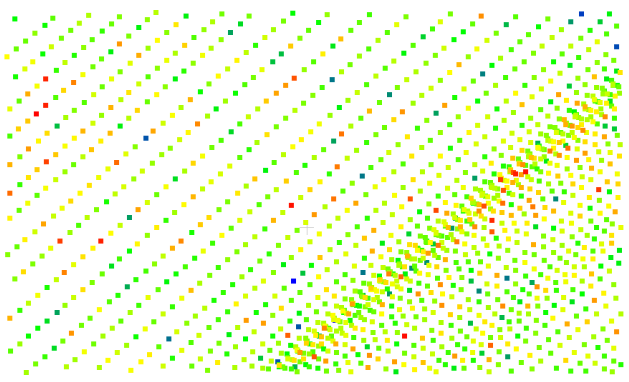

Figure 6. Map of deviations - UAV point cloud

Tables 4 and 7 contain average values for test fields, respectively small and large.An analysis of point cloud distances to fitted plane was carried out using method Cloud to Mesh $(\mathrm{C} 2 \mathrm{M})$. The results were diagrams of point's distances from surfaces (Figure 5, 6). Histograms (Figure 7,8) presenting point deviations from plane 3 show, that distribution of deviations is random and even in both cases. The obtained mean values of deviations for the UAV method are twice smaller than those obtained from airborne Lidar. The density of the Lidar cloud is four times higher than planned $\left(4.3 \mathrm{pt} / \mathrm{m}^{2}\right)$, this is due to good exposure and lack of obscuration. The results indicate that in the case of larger fields, the values of the maximum deviations are almost equal, however, the proportion of mean distance values and their standard deviations is maintained.

signed distances (187 values) [12 classes]

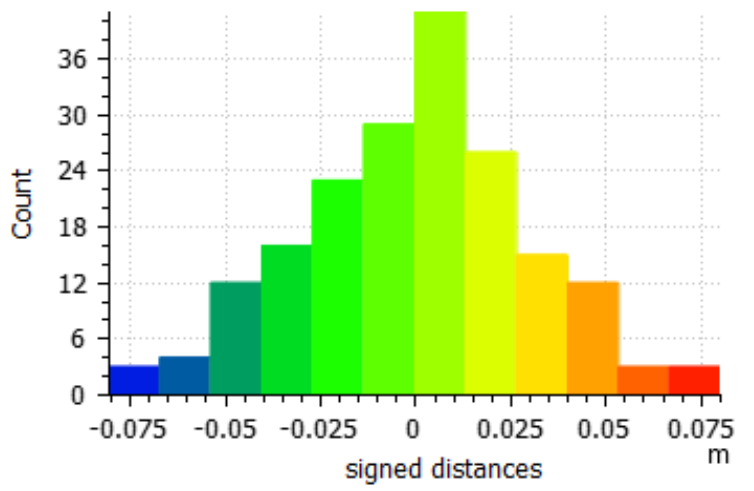

Figure 7. Histogram of deviations from plane3- Lidar signed distances (1456 values) [36 classes]

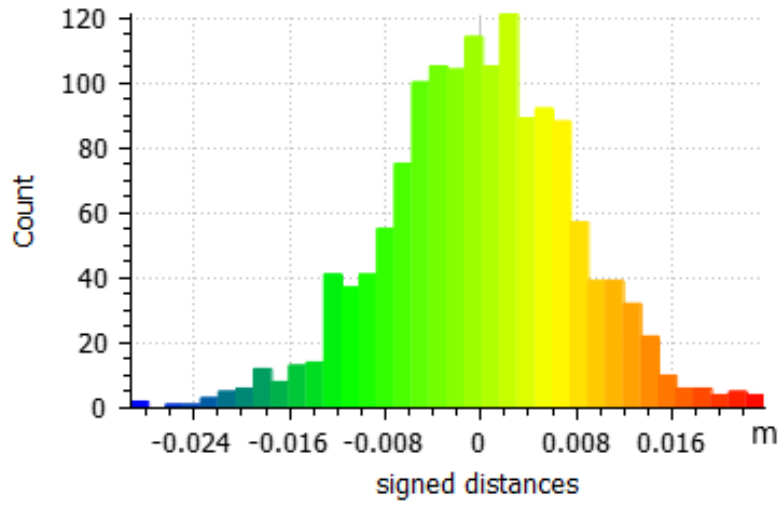

Figure 8. Histogram of deviations from plane3- UAV

Another analysis was the creation of a cross-section through the bridge span. (Figure 9, 10, 11) A cross-section of a point clouds of $10 \mathrm{~cm}$ thickness shows the difference in density of the object's coverage. It is possible to observe the elevation difference between the cloud obtained from UAV and Airborne Lidar that is on average $11 \pm 3 \mathrm{~cm}$ (Figure 11).

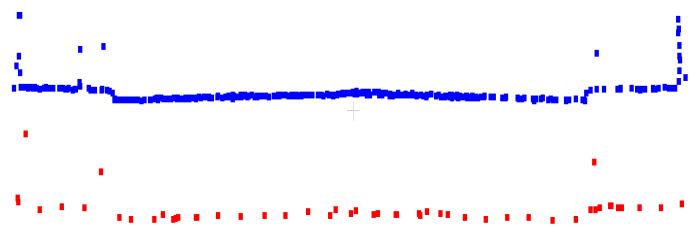

Figure 9. Cross-section of bridge span from UAV (upper). Cross-section of bridge span from Lidar (lower)

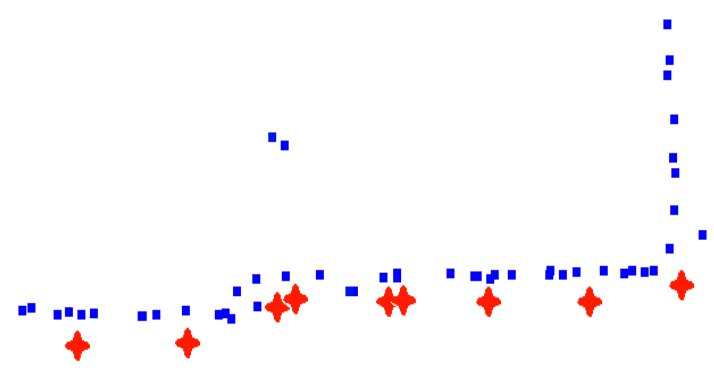

Figure 10. UAV and Lidar clouds cross-section close-up (crosses - Lidar, points - UAV)

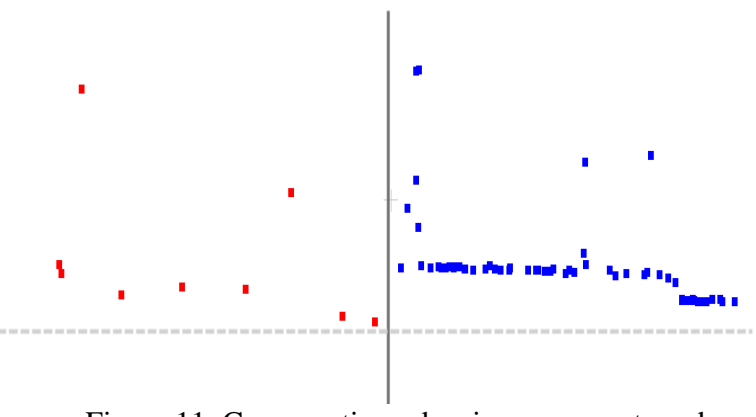

Figure 11. Cross section - barrier, pavement, curb (left - Lidar, right - UAV) 


\subsection{Conclusions}

The result of the conducted analyzes confirms the advantages of using UAV mounted Lidar. On a small scale of individual objects such as bridges, a low altitude airborne laser scanning can provide a dense coverage of the object even if it was within a range of one scan line. It can be noticed by observing the pattern created by the point cloud on the surface of the object. The pattern depends on the path of the flight and the instantaneous velocity of the UAV relative to the ground. The cloud obtained by this method is uniform and clearly coherent. Values of both mean distance of point cloud to regression plane and its standard deviation is two times lower. The quality of the data enables surface modeling and recognition of construction details, such as curbs, barriers and handrails, or when recognizing horizontal markings.

The better results in case of point cloud density and precision of reproduction of the objects still can be obtained. This requires designing a measurement to match the tested object, which is allowed by the characteristics of the UAV measurement.

\section{CASE 2 - LATTICE TRANSMISSION TOWER}

The main reason of taking measurements of transmission towers is need of regular, periodic monitoring. The methods, that are well established in monitoring and measuring of transmission towers and powerlines corridors comprises terrestrial field survey and aerial mapping. These methods evolved from teams of engineers performing checking of foot or from helicopters (that methods are still in use). Both methods had theirs pros and cons. Monitoring from ground was laborious but was not restricting time of inspection, whereas helicopter inspection was more efficient, but it was limiting observation time. Nowadays these visual based methods are more and more often replaced by mapping technology. This solution allowed to gather data on site and analyse it later. We are able to distinguish several methods of measurements: ground based survey, terrestrial laser scanning and aerial methods that include photogrammetric approach and Lidar. Today use of UAV carrying photographic cameras have become popular in monitoring power lines (Matikainen, L., et al., 2016; Moore, A.J., et al., 2017; Jiang, S., et al., 2017).

Just as in the case of mentioned visual methods, general rule remains the same. Ground based methods can be precise but require high effort and are time consuming. On the other hand, traditional aerial measurement is more efficient in terms of mapped area, but cannot be as adapted to object as terrestrial measurements. Due to high cost of single measurement, airborne missions have to be designed on bigger areas to make it profitable.

Study of Teng, G. E., et al., 2017 presents application of UAV based mini Lidar in inspection of high voltage lines in inaccessible terrain, where other methods are not efficient or profitable.

This part of the paper focuses on use of airborne Lidar in power lines monitoring. To compare data from plane and UAV Lidar two point clouds of the same object were gathered.

\subsection{Parameters of Lidar and UAV gathered data}

Metadata of Lidar origin point cloud describes typical values of parameters of flight. Planes maximum velocity during scanning should not exceed $40 \mathrm{~m} / \mathrm{s}$. Pattern of flight was set of parallel scanlines $640 \mathrm{~m}$ apart from each other on 850m AGL.

UAV measurements was planned as grid pattern of lines $80 \mathrm{~m}$ apart from each other on $70 \mathrm{~m}$ AGL. The condition of sidelap coverage of scans at the level of approx. 50\% has been preserved - the data acquisition region of 120 degrees was used, as in the case of the bridge measurements in case 1 . The planned cruising speed was $10 \mathrm{~m} / \mathrm{s}$.

Measured object was the first tower from electrical substation. Its height was $32 \mathrm{~m}$ and $11 \mathrm{~m}$ span of its cross arms. Horizontal distance to the nearest tower, and span of the powerlines was $120 \mathrm{~m}$.

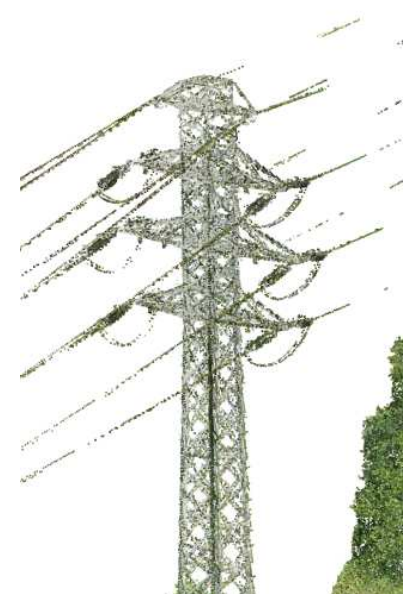

Figure 12. Isometric view of transmission tower - UAV

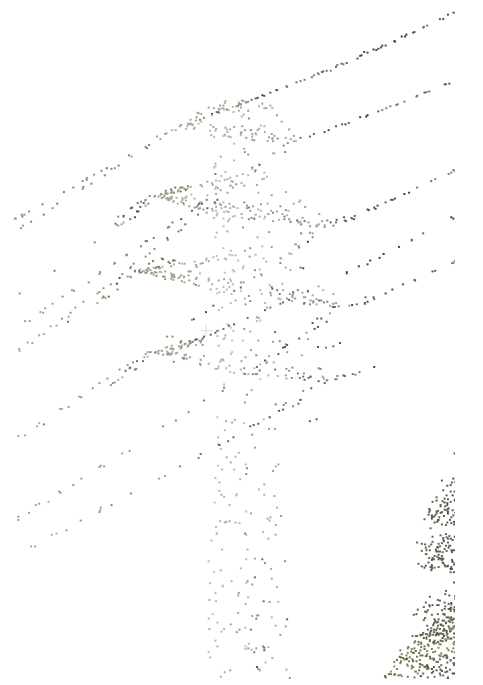

Figure 13. Isometric view of transmission tower - Lidar

(Figure 12) and (Figure 13) show the identical elements from measurement in two methods, respectively high and low AGL scanning, depicting difference in density of point clouds. On the orthogonal view of the transmission tower (Figure 14) difference in captured detail can be noticed. The cloud from Lidar allows the location of the structure and surroundings (Kwoczyńska, B.; Dobek, J., 2016), and can also be used to 
measure cables (deflection measurement) (Matikainen, L., et al., 2016). In addition to the observed higher density of clouds on the ground surface, the UAV cloud provides higher spatial resolution on the object, where individual elements can be distinguished.
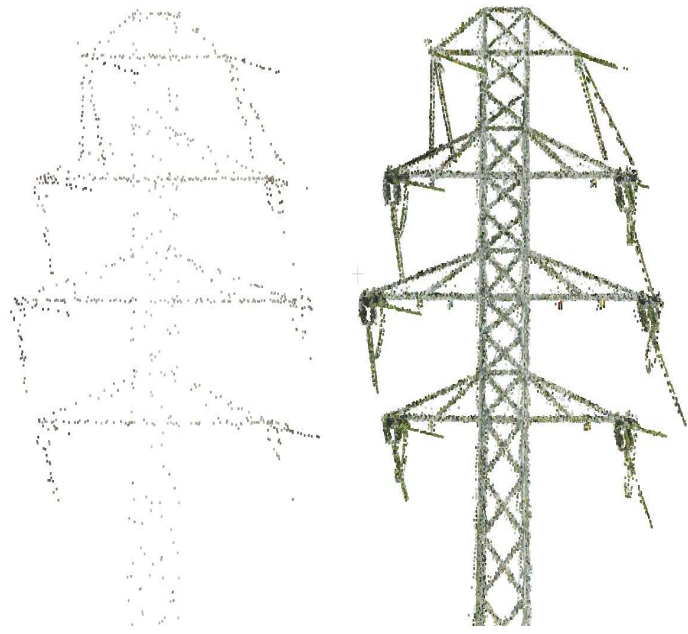

Figure 14. Orthogonal view of the transmission tower (Left - Lidar, Right - UAV)

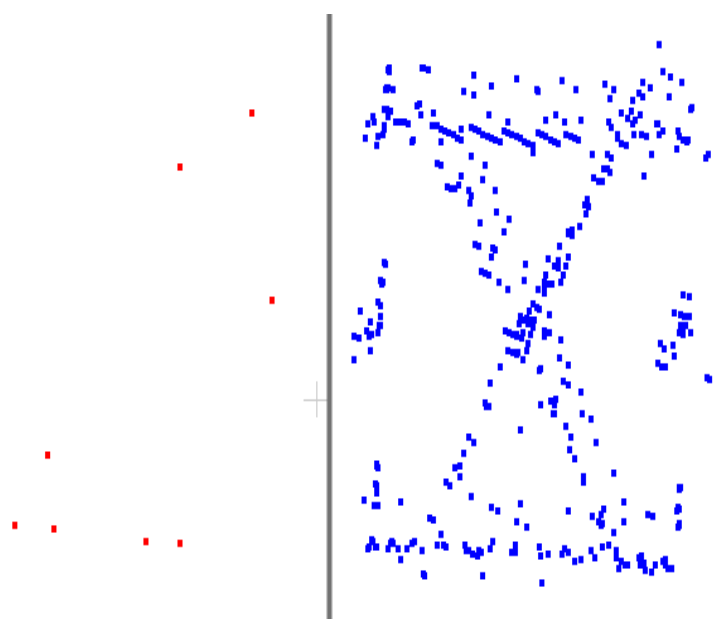

Figure 15. Horizontal cross-section of the truss (Left - Lidar, Right - UAV)

Point clouds from Lidar and UAV were cut with a horizontal section with a thickness of $20 \mathrm{~cm}$. The resulting cross-sections are shown in Figure 15. The cross-section from the UAV was 420 points, and from Lidar, 8 points. The difference in density was caused with geometry of the UAV flight, allowing measurements from different sides and angles. The Lidar point cloud does not give the possibility to recognize elements in this case. In UAV cloud distinctly recognizable are typical elements of the structure: wires, insulators and the construction of the tower, truss of individual beams. (Figure 15) shows point cloud classified manually based on the visual recognition.

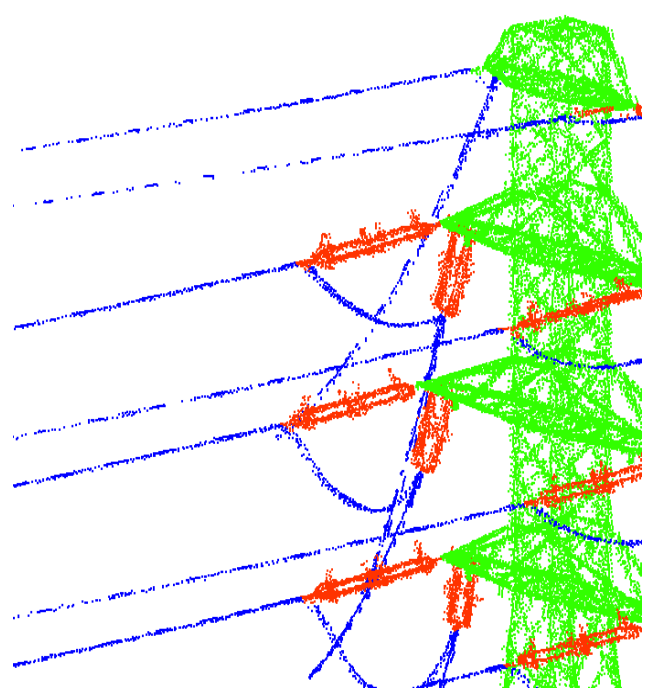

Figure 16. Classification of the structural elements on UAV point cloud (conductors, isolators, truss)

\subsection{Conclusions}

The quality parameters of point clouds obtained from both methods indicate the difference in possible applications of measurement methods. The key is to adjust the method and choose the right one for the intended purpose.

Airborne Lidar is characterized by high efficiency, it is performed for large areas, e.g. entire administrative units. It is possible to plan mission adapted not only to surface measurements, but also corridors (roads, transmission network) (Yen, Kin S., et al., 2011). This is related to the typical parameters of the aircraft - high speed, high altitude and considerable range. The disadvantage of this solution, in addition to high take-off costs and reaching the measurement location, is the lower limit altitude, which is a cause of the limitation of the accuracy and density of the scan. The minimum altitude is limited due to the terrain denivelations, economic considerations and aviation law.

The use of UAV to carry the laser scanner brings the airborne scanning features to terrestrial scanning. It combines the field of view of aerial measurements with measurements at a closer distance. This technology also has some limitations. It allows you to adapt the survey to a specific object, but a short flight time forces planning of multiple starts for larger objects. In the case of UAV scanning there is an opposite limitation to airborne Lidar - UAV cannot rise too high to reduce the point cloud density in order to cover a larger area with single scan. This is the result of both the construction characteristics - range and flight time, vulnerability to harsher atmospheric conditions at a higher level, and legal restrictions - in Poland unmanned flights are limited to $150 \mathrm{~m}$ above the ground surface. However, with less effort than with terrestrial scanning, it is possible to quickly obtain a dense, internally consistent point cloud, suitable, for example, for periodic monitoring of the condition of the structures under examination. 


\section{DISCUSSION}

The study involved data obtained using the same measurement technology, made by the same manufacturer. The Mobile Scanning System - mounted on the UAV platform is a miniature of systems mounted on manned aircraft. Apart from their size, the geometry of the measurement also differs. Field of view of the airborne Lidar covers only small angle range and it is pointed directly downwards, whereas UAV mounted Lidar can take measurements of objects theoretically located above the scanner, which allow it to measure objects restricted from other methods. The scale of the measurement, focused on single or grouped objects at a short distance, allows adjusting the plan of the flight to best match the examined object.

Many factors influence the final measurement accuracy. Trajectory and positioning errors, scanning errors - angle and distance measurements. The difference in distance and range at which the measurement is performed (about 5-10 times smaller distance in the case of UAV) affects both the values of the errors transmitted on objects surface and the spatial resolution defined by the size of the laser beam footprint.

\section{CONCLUSIONS}

Low altitude scanners are miniaturised airborne equipment. They have some lower parameters of range and power than their counterparts. Despite this, due to closer location of measured objects and better suited geometry of measurement and smaller beam footprint it can provide data of higher density, bigger spatial resolution and greater consistency of point cloud. This method combines some advantages of aerial and terrestrial laser scanning: unrivalled field of view with precision and versatility, mobility.

These features make this method proficient for use in mapping and inspection of infrastructure objects.

\section{ACKNOWLEDGEMENTS AND APPENDIX}

Special thanks to the Lidar3d Company for providing UAV system to conduct a survey.

\section{References}

AICARDI, I., et al., 2016. UAV photogrammetry with oblique images: first analysis on data acquisition and processing. International Archives of the Photogrammetry, Remote Sensing \& Spatial Information Sciences, 41.

Bolourian, N., et al., 2017. High Level Framework for Bridge Inspection Using LiDAR-equipped UAV. In: ISARC. Proceedings of the International Symposium on Automation and Robotics in Construction. Vilnius Gediminas Technical University, Department of Construction Economics \& Property 3. Brede, B., et al., 2017. Comparing RIEGL RiCOPTER UAV LiDAR derived canopy height and DBH with terrestrial LiDAR. Sensors, 17.10: 2371.

Colomina, I., \& Molina, P., 2014. Unmanned aerial systems for photogrammetry and remote sensing: A review. ISPRS Journal of photogrammetry and remote sensing, 92, 79-97.
Ham, Y., et al., 2016. Visual monitoring of civil infrastructure systems via camera-equipped Unmanned Aerial Vehicles (UAVs): a review of related works. Visualization in Engineering, 4.1: 1.

Hutton, J., et al., 2007. New developments of inertial navigation systems at Applanix. Photogrammetric Week'07, 201-213.

Jiang, S., et al., 2017. UAV-based oblique photogrammetry for outdoor data acquisition and offsite visual inspection of transmission line. Remote Sensing, 9.3: 278.

Kukko, A. et al., 2012. Multiplatform Mobile Laser Scanning: Usability and Performance. Sensors (Basel, Switzerland) vol. 12, 9 11712-11733.

Kwoczyńska, B.; Dobek, J., 2016. Elaboration of the 3D Model and Survey of the Power Lines Using Data from Airborne Laser Scanning. Journal of Ecological Engineering, 17.4.

Matikainen, L., et al., 2016. Remote sensing methods for power line corridor surveys. ISPRS Journal of Photogrammetry and Remote Sensing119: 10-31.

Mian, O., et al., 2015. Direct georeferencing on small unmanned aerial platforms for improved reliability and accuracy of mapping without the need for ground control points. The international archives of photogrammetry, remote sensing and spatial information sciences, 40.1: 397.

Moore, A.J., et al., 2017. UAV Inspection of Electrical Transmission Infrastructure with Path Conformance Autonomy and Lidar-based Geofences NASA Report on UTM Reference Mission Flights at Southern Company Flights November 2016. https://ntrs.nasa.gov/archive/nasa/casi.ntrs.nasa.gov/201700110 48.pdf (view at 20 Oct. 2018).

Rau, J. Y., et al., 2017. Bridge Crack Detection Using MultiRotary Uav and Object-Base Image Analysis. The International Archives of Photogrammetry, Remote Sensing and Spatial Information Sciences 42311.

Teng, G. E., et al., 2017. Mini-UAV lidar for power line inspection. ISPRS-International Archives of the Photogrammetry, Remote Sensing and Spatial Information Sciences, 297-300.

Valença, J., et al., 2017. Assessment of cracks on concrete bridges using image processing supported by laser scanning survey. Construction and Building Materials 146): 668-678.

Yen, Kin S., et al., 2011. LiDAR for data efficiency. Washington (State). Dept. of Transportation. Office of Research and Library Services.

\section{References from websites:}

RIEGL 2017, VUX-1 UAV Datasheet. http://www.riegl.com/uploads/tx_pxpriegldownloads/RIEGL_V UX-1UAV_Datasheet_2017-09-01.pdf (view at 20 Oct. 2018). 
RIEGL 2012, LMS-Q680i Datasheet

http://www.riegl.com/uploads/tx_pxpriegldownloads/10_DataS

heet_LMS-Q680i_28-09-2012_01.pdf (view at 20 Oct. 2018). 